\title{
Distribution and Pathogenic Characterization of Pyrenophora tritici-repentis and Stagonospora nodorum in Ohio
}

\author{
Jessica S. Engle, Laurence V. Madden, and Patrick E. Lipps
}

First author: Former Graduate Research Associate; second author: Professor; and third author: Professor Emeritus, Department of Plant Pathology, The Ohio State University, Wooster 44691.

Current address of J. S. Engle: U.S. Department of Agriculture, North Carolina State University, Raleigh 27695-7616.

Accepted for publication 8 July 2006.

\begin{abstract}
Engle, J. S., Madden, L. V., and Lipps, P. E. 2006. Distribution and pathogenic characterization of Pyrenophora tritici-repentis and Stagonospora nodorum in Ohio. Phytopathology 96:1355-1362.

To determine the distribution of Stagonospora nodorum and Pyrenophora tritici-repentis on wheat in Ohio, flag leaves with lesions were collected from wheat-producing counties in 2002 and 2003. Counties were arbitrarily grouped into seven regions. Log-linear analysis of pathogen presence within regions indicated that the presence of $S$. nodorum was independent of the presence of $P$. tritici-repentis. A logistic analysis revealed that the occurrence of both pathogens varied by region in one or both years. The aggressiveness of $S$. nodorum isolates was determined by inoculating two susceptible genotypes with a subsample of isolates from each region from both years. S. nodorum isolates obtained from northeast

other regions did not differ significantly $(P>0.05)$ in aggressiveness. Races 1 and 2, and a few race 3 isolates, of $P$. tritici-repentis were detected in Ohio. The distribution of $P$. tritici-repentis races 1 and 2 was not associated with any region, although the prevalence of race 1 was three times greater than race 2 . The rarer race 3 was associated with three dispersed regions. Results indicate that $S$. nodorum was the major wheat leaf-blotching pathogen. There were no positive or negative associations of $S$. nodorum and $P$. tritici-repentis or individual races of $P$. triticirepentis in any of the tested regions, which indicates that neither pathogen can be used to predict the presence of the other. The isolated northeastern corner of Ohio appeared to contain isolates of $S$. nodorum with unique characteristics and potentially only one race of $P$. tritici-repentis, indicating that this area may be genetically isolated from the remaining tested areas of the state.
\end{abstract} Ohio, with fewer wheat fields, were less aggressive than those from other regions. Isolates obtained from west-central Ohio, surrounded by regions with high wheat production annually, were significantly more aggressive than those obtained in the remaining five regions. Isolates from the five
Additional keywords: Drechslera tritici-repentis, Phaeosphaeria nodorum, Triticum aestivum.
The wheat (Triticum aestivum L.) foliar pathogens Stagonospora nodorum (Berk.) (Castellani and E. G. Germano) (teliomorph Phaeosphaeria nodorum (E. Muller (Hedjaroude))) and Drechslera tritici-repentis (Died.) (Shoemarker) (teliomorph Pyrenophora tritici-repentis (Died.) (Drechs)) are common throughout wheat-growing regions of the world (47). S. nodorum causes Stagonospora leaf and glume blotch on wheat and other cereals. Pyrenophora tritici-repentis causes tan (or yellow) spot of wheat. The prevalence and intensity of disease caused by these pathogens depend on environmental factors.

S. nodorum became one of the major wheat leaf spotting pathogens in the Midwest by the late 1980s, coinciding with the increase of conservation tillage (42). In the Northern Great Plains of North America, tan spot is considered one of the major foliar diseases of wheat, with increased occurrence in recent decades after the adoption of conservation tillage $(1,34,35,47)$. Both diseases affect grain quality and yield. Yield may be reduced as the result of lower test weights (32) due to reduced photosynthetic area of the upper leaves, resulting in decreases in the level of carbohydrates available for seed fill (19), lower thousand-kernel weight, and reduced number of grains per head $(5,6)$. The milling quality of grain may be reduced by infection of the developing seed, causing shriveling, discoloration, and reduced flour yield

Corresponding author: J. S. Engle; E-mail address: engle.39@osu.edu

DOI: 10.1094/PHYTO-96-1355

(c) 2006 The American Phytopathological Society
$(5,6,19)$. Infection of wheat plants by $S$. nodorum may occur at any stage of development (45).

Management of Stagonospora leaf blotch and tan spot is achieved through cultural practices, fungicide application, and the use of resistant cultivars $(6,21,31,36,44)$. Primary cultural practices include crop rotation combined with burying infested residue by tillage to reduce the survival of the fungus from one crop to the next $(2,6,21,31,36,44)$. Control of seedborne inoculum is achieved through application of fungicide seed treatments to reduce seed infection $(2,20,27,31,39,40)$. Application of foliar fungicides can be effective in managing disease in epidemic years; however, cost can be economically prohibitive when the price of wheat is low $(6,26,31,36,45)$. Moderately resistant cultivars are available but, currently, there are no soft red winter wheat cultivars with high levels of resistance to $S$. nodorum (26). Resistance to $S$. nodorum has been shown to be quantitatively inherited $(10,14,25,37,38,44)$. Genetic resistance in commercial cultivars is considered the most environmentally safe and economical means of tan spot management $(15,35,36)$. The specific genes controlling resistance and the level of resistance expressed for the seedling and leaf phases of this disease have been investigated (13). Most studies concur that resistance to $P$. tritici-repentis is controlled by a few major genes for toxin sensitivity, and these and other minor genes condition expression of partial resistance to other virulence factors (17).

$S$. nodorum has been the subject of numerous population studies. These studies were focused on determining the spatial variation in aggressiveness among both large-scale geographical areas and genetically different isolates within lesions (38). Mo- 
lecular marker technology has been used to examine the genetic structure of $S$. nodorum populations within a field under epidemic conditions (20). Results substantiated the hypothesis that initiation of epidemics was not through seed source or the cultivars planted but by genetically different isolates from other inoculum sources, such as spore clouds from distant fields (20). In an examination of relative virulence frequency among geographically separated populations of $S$. nodorum, Scharen et al. (38) found that isolates from Europe, South America, and Canada had lower virulence than isolates from the United States (38). Aggressiveness of $S$. nodorum isolates is thought to be the main determinate of cultivar reactions, with less aggressive isolates not discriminating resistant and susceptible reactions (37).

$P$. tritici-repentis exists as eight different races and is capable of producing at least three phytotoxins $(1,8,23)$. The most abundant races in the United States have been race 1 and race 2, with some occurrences of races 3,4 , and $5(1,16)$. Races 6 to 8 have been found in other areas of the world $(1,23)$. Two distinct types of symptoms develop on susceptible cultivars subsequent to infection, tan necrosis or chlorosis as a response to toxins produced by $P$. tritici-repentis $(23,47)$. The necrosis toxin is $P \operatorname{tr} \operatorname{ToxA}(23,28)$ and the chlorosis toxins are Ptr ToxB $(16,23,29,47)$ and Ptr ToxC (23). Wheat nuclear genes control reactions to all races and toxins produced (17). Additional virulence factors apparently influence disease severity, but these have not been well characterized $(15,16,23)$.

Environmental conditions in Ohio favor infection and spread of $S$. nodorum in wheat fields, making leaf blotch resistance a preferred management tool. In some years, frequent precipitation events after head emergence favor leaf blotch development and subsequent development of glume blotch. Monitoring Stagonospora leaf blotch progression through the season has proven difficult in Ohio and other parts of the world due to the occurrence of $P$. tritici-repentis that causes tan spot with similar lesions (5). The occurrence and distribution of $P$. tritici-repentis races in

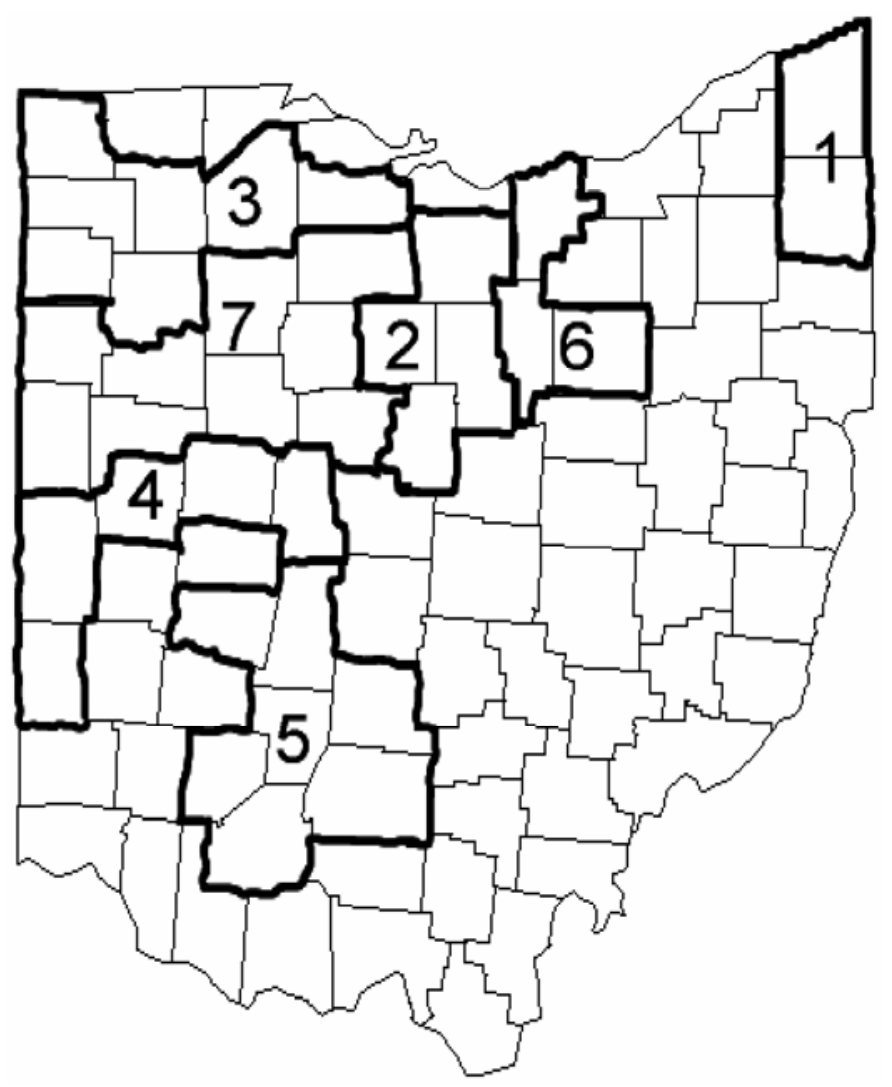

Fig. 1. Map of Ohio with sampled regions outlined.
Ohio has not been studied. No information is available on the occurrence of specific $P$. tritici-repentis races in most soft red winter wheat-growing regions of the United States. This lack of knowledge may be affecting the selection of highly resistant germ plasm in the Ohio State University wheat-breeding program because coinciding infections by $P$. tritici-repentis and $S$. nodorum may not be readily distinguished in field disease screening nurseries.

The objectives of this study were to (i) determine the distribution of the predominant wheat leaf-blotching pathogens in Ohio, (ii) evaluate the association between the leaf-blotching pathogens, (iii) determine the variation in aggressiveness of $S$. nodorum populations across the different regions of Ohio, and (iv) determine the race structure of $P$. tritici-repentis within Ohio.

\section{MATERIALS AND METHODS}

Collection of leaf samples. A form of stratified random sampling (43) was utilized in 2002 and 2003 to obtain flag leaf samples form wheat fields in Ohio. Strata consisted of the seven wheat-growing regions in the state, with borders set arbitrarily by county borders (Fig. 1). The seven regions were: Region 1 (northeast), Ashtabula and Trumbull Counties; region 2 (north-central), Crawford, Huron, Morrow, and Richland Counties; region 3 (northwest), Defiance, Henry, Paulding, Putnam, Sandusky, Williams, and Wood Counties; region 4 (southwest) Darke, Logan, Preble, Shelby, and Union Counties; region 5 (south), Clark, Clinton, Fayette, Highland, Madison, Pickaway, and Ross Counties; region 6 (north-central-east) Ashland, Lorain, and Wayne Counties; and region 7 (west-central) Allen, Auglaize, Hancock, Hardin, Marion, Mercer, Seneca, Van Wert, and Wyandot Counties. The number of fields sampled per region was roughly proportional to the area of wheat grown in each county (using 2001 production-year statistics). Fields in 37 and 35 counties were sampled in 2002 and 2003, respectively. As many as 15 fields per county were sampled during the period from flowering through senescence (Feekes growth stages 10.5.4 to 11.1) (24).

Three flag leaves with lesions were collected from each field. Leaves were collected at least $1 \mathrm{~m}$ apart within a $3.3-\mathrm{m}$ radius from the field edge. Leaves heavily infected with rust (Puccinia triticina (DC.) E. O. Speer) or powdery mildew (Blumeria graminis f. sp. tritici (Ericks)) were discarded. The leaves were placed in coin envelopes and dried in an air-flow hood for $\approx 2$ days after collection (11). Long-term storage was at room temperature in a plastic container.

Isolation of pathogens. Flag leaf samples were placed in moisture chambers to enhance sporulation of leaf-blotching pathogens. Chambers consisted of 9-cm-diameter Pyrex petri dishes containing 9-cm-diameter filter paper moistened with $5 \mathrm{ml}$ of water underneath a 6-by-6-cm wire mesh screen that supported a glass slide. The glass slide had two pieces of doublesided sticky tape for adherence to leaves to prevent rolling.

Leaves were disinfested in a solution of $10 \%$ bleach $(5.25 \%$ sodium hydrochlorite; Snow-EE, Mars, PA) (11). Chambers were placed under a bank of fluorescent and ultraviolet lights for $48 \mathrm{~h}$ before the first isolation attempt and $72 \mathrm{~h}$ before the second isolation attempt. For each field sample, a $5-\mathrm{cm}$ section of one leaf was placed in each moisture chamber. Leaf sections were chosen based on the presence of discrete lesions and with the least amount of senescence. A second set of leaf sections were prepared similarly. The two different isolation attempts per field sample were recorded separately.

Each leaf section was removed from the moisture chamber to a dissecting scope in a laminar air-flow bench. A sterile sewing needle was employed to lift the spore mass from a single conidiophore and placed on V8 agar amended with streptomycin sulfate (Sigma-Aldrich, St. Louis) at $50 \mathrm{mg} / \mathrm{liter}$. Four isolation attempts 
were made from each leaf. The leaf sections were placed back into the moisture chambers and the 72-h isolation attempt was made the next day. This second isolation attempt was done because the first isolation did not consistently provide uncontaminated, mature spores.

Isolation plates were placed under the bank of lights previously described until fungal species could be determined. Contaminated colonies were transferred further until free of contaminants. Once a fungal isolate was contaminant free, a single spore isolation was made. The species was determined by pycnidium, conidia, and colony morphology $(12,48)$, then placed in storage.

Pyrenophora tritici-repentis race determination. A subset of 37 Pyrenophora tritici-repentis isolates collected in 2002 was sent to T. Friesen at the U.S. Department of Agriculture (USDA) Agricultural Research Service Red River Valley Agriculture Research Center (Fargo, ND) for race determination. A single isolate from each county was placed on a set of differential wheat cultivars (Table 1) to determine race. Dried plugs of each isolate in Eppendorf tubes were shipped (USDA-APHIS permit no. 61766) in a sealed container. Race determination was repeated in Ohio as described below with a subset of the 2002 collection (18 isolates) and the 2003 collection (46 isolates).

Seed of the six differential cultivars and lines (Table 1) were obtained from Dr. Friesen and maintained at $3.5^{\circ} \mathrm{C}$ until use. Two seed of each cultivar or line were placed into 20.5 -by-4-cm conetainers (Stuewe and Sons, Inc., Corvallis, OR) of 3M Metro Mix (Conrad Fafard, Inc., Agawam, MA). The seed were germinated in a $44.5-\mathrm{m}^{2}$ greenhouse maintained with average temperatures of 20.8 and $19.2^{\circ} \mathrm{C}$ (day and night), with a 12-h light period provided by one 1,000-watt metal halide lamp and four 1,000-watt high-pressure sodium lights (Rudd Lighting Co., Solon, OH). During the course of the experiment, pots were fertilized weekly with $100 \mathrm{ml}$ of a triple-20 Peter's fertilizer solution (20\% each N, $\mathrm{P}$, and $\mathrm{K} ; 4.8 \mathrm{~g} /$ liter of water) (Scotts, Inc., Marysville, $\mathrm{OH}$ ). For insect control, plants were sprayed weekly with S-kinoprene (Enstar, $0.01 \mathrm{~g}$ a.i./liter of water) or abamectin (Avid, $0.01 \mathrm{~g}$ a.i./ liter of water).

P. tritici-repentis inoculum and inoculation. Seedlings were inoculated when they were 2 weeks old, at approximately the two-leaf stage. Inoculum consisted of a $3 \times 10^{3}$ conidia/ml suspension of individual $P$. tritici-repentis isolates. Two-week-old cultures in petri dishes were washed with tap water, and the mycelial mat with conidia was scraped from the surface of cultures grown on amended V8 agar, then strained through two layers of cheese cloth. Spore numbers were determined using a hemacytometer. The inoculum was atomized with a hand mister onto the surface of the leaves to the point of runoff. Control inoculations consisted of a set of the differentials inoculated with a confirmed race 1 isolate and another set inoculated with a race 2 isolate for each repetition.

After inoculation, plants were placed into a mist chamber for $24 \mathrm{~h}$ (11). The temperature in the mist chamber was maintained at $\approx 22^{\circ} \mathrm{C}$ and the relative humidity was $\approx 100 \%$. After incubation, conetainers were returned to the greenhouse. Seedlings were assessed visually after inoculation for symptom development daily and examined for disease symptoms 7 days after inoculation. The lesion rating system of Lamari and Bernier was used for determining the reactions, which accounts for chlorosis and necrosis symptoms (22).

S. nodorum aggressiveness. A subset of $S$. nodorum isolates from the 2002 (34 isolates) and 2003 (46 isolates) collections was evaluated for aggressiveness. An individual isolate was spread on a V8 plate with a sterile bent glass rod and placed under the light bank as described previously. After 1 week, pycnidiospores were harvested from plates. The 8-cm-diameter agar discs of each isolate were inverted onto a $15-\mathrm{cm}$ square of cheesecloth (four layers), placed into glass beakers of tap water $(100 \mathrm{ml})$ for several minutes, dipped several times, and then squeezed to release pycnidiospores. Conidial suspensions then were adjusted to $1 \times$ $10^{6}$ spores/ml using a hemacytometer.

The susceptible hard red spring wheat line ND2375 and susceptible soft red winter wheat cv. AGRA GR863 were used for evaluating isolate aggressiveness. Seed of ND2375 was obtained from the North Dakota State University and maintained at $3.5^{\circ} \mathrm{C}$ under low humidity. Two seed were sown in each conetainer of 3M Metro Mix. Conetainers were placed in the greenhouse as described previously. Two weeks after planting, at approximately the two-leaf stage, seedlings were inoculated. For each isolate, 10 plants each of ND2375 and of AGRA GR863 were inoculated. Each repetition had control inoculations of two isolates, SN8 and SN39, which were isolated during 2002. Both of these isolates created a moderately susceptible reaction when inoculated onto the susceptible test lines.

The spore suspensions from individual $S$. nodorum cultures were sprayed onto the seedlings to the point of run-off with an atomizer. After inoculation, the seedlings were allowed to dry for $1 \mathrm{~h}$ before being placed in the misting chamber for $48 \mathrm{~h}$. After incubation, seedlings were returned to the greenhouse. Seedlings were examined daily for symptom development and visually rated for disease severity 7 days after inoculation. The lesion rating scale of Liu et al. (25) was used to determine reaction type.

Statistical analysis-survey of fields. Each isolate of both species was coded for geographic region to determine whether prevalence of leaf-blotching pathogens from diseased leaves was related to region and whether there was an association of the two pathogens on diseased leaves. Analogous to the concept of disease prevalence in Nutter (33), we consider pathogen prevalence and pathogen occurrence to represent the proportion of fields in which the pathogen of interest was isolated from a diseased leaf. Binary variables were defined for the presence or absence of $S$. nodorum and $P$. tritici-repentis in each field.

A logistic model was fitted to the occurrence (presence or absence) data for each pathogen species using maximum likelihood, with region as a factor (i.e., class) variable (9). The CATMOD procedure of SAS (version 9.1; SAS Institute, Cary, NC) was used for the analysis. It was assumed that the binary variable had a binomial distribution $(9,30)$. A likelihood ratio test was used to determine whether region significantly affected the occurrence of each pathogen in diseased wheat leaves. The likelihood ratio was compared with a $\chi^{2}$ value to determine significance. Maximum

TABLE 1. Differential cultivars and lines used for Pyrenophora tritici-repentis race determination

\begin{tabular}{|c|c|c|c|c|}
\hline \multirow[b]{2}{*}{ Cultivar or line ${ }^{a}$} & \multicolumn{4}{|c|}{ Reaction } \\
\hline & Race 1 & Race 2 & Race 3 & Race 5 \\
\hline Glenlea & Necrosis & Necrosis & Resistant & Resistant \\
\hline Katepwa & Necrosis & Necrosis & Resistant & Chlorosis \\
\hline Salamouni & Resistant & Resistant & Resistant & Resistant \\
\hline M3 & Resistant & Resistant & Resistant & Resistant \\
\hline ND495 & Necrosis & Necrosis & Resistant & Resistant \\
\hline $6 \mathrm{~B} 365$ & Chlorosis & Resistant & Chlorosis & Resistant \\
\hline 6B662 & Resistant & Resistant & Resistant & Chlorosis \\
\hline
\end{tabular}

a Reactions as reported in Ali and Francl (1). 
likelihood estimates of model parameters were used (after transformation) to determine the estimated probability of pathogen occurrence in each region, and contrasts of the estimated logits for each region were used to determine significant differences in the probability of occurrence between regions. A separate analysis was done for each year.

A log-linear model was fitted to the joint occurrence (presence or absence) data for both species using maximum likelihood (30). The CATMOD procedure of SAS was used for the analysis. In the log-linear model, the response variable was the count of number of fields with a given combined pathogen occurrence: neither pathogen found, both pathogens found, S. nodorum only found, and $P$. tritici-repentis only found. It was assumed that the count had a Poisson distribution $(9,30)$. Predictor variables were region, indicator variables for $S$. nodorum and $P$. tritici-repentis occurrence, and their interactions. Likelihood ratio tests were used to determine significant effects. A significant interaction of the pathogen indicator variable and region in the log-linear model is the same as a significant main effect of region in the logistic model above. (Log-linear models could have been used instead of logistic models for the occurrence analysis, above; however, it was more efficient to use logistic analysis for making pairwise comparisons of regions.) Of particular relevance here is the interaction of the indicator variables for the two species, which would indicate whether there was a significant association of the occurrence of the two species in the sampled wheat fields. If the occurrence of the two species was independent (i.e., the presence of one pathogen species neither increased nor decreased the probability that the other species is present), then the interaction term would not be significant. An additional likelihood ratio test was performed for goodness-of-fit of the model to the data. Likelihood ratios were compared with $\chi^{2}$ values to determine significance. A separate analysis was done for each year.

Statistical analysis- $\boldsymbol{S}$. nodorum aggressiveness. To determine whether aggressiveness of $S$. nodorum isolates varied by region and year of isolation, a nonparametric marginal effects analysis was performed on the lesion rating measurements $(7,41)$. This nonparametric procedure is appropriate for ordinal measurements (such as the 1-to-5 rating scale used here) and continuous measurements scale $(18,41)$. Region, cultivar, and year were considered fixed effects. A so-called analysis of variance-type statistic was used for testing for fixed effects (7). Pathogen aggressiveness for each region was represented by the estimated relative marginal effect, $p$, which is a statistic (varying between 0 and 1) that summarizes the entire distribution of rating values for each region relative to the distribution of ratings for all regions combined (41). Contrasts were used to compare the $p$ values between regions. The MIXED procedure of SAS, with options explained by Shah and Madden (41), was used for this analysis. For presentation purposes, the median disease ratings also were calculated.

\section{RESULTS}

Distribution of leaf-blotching pathogens. In 2002 and 2003, 359 and 368 fields, respectively, in seven designated wheatgrowing regions of Ohio were sampled (Fig. 1; Table 2). In 2002, 125 fields had neither $S$. nodorum nor $P$. tritici-repentis, whereas only 50 fields in 2003 had neither pathogen (Table 3). Both pathogens were recovered from flag leaves from 54 fields in 2002 and 50 fields in 2003.

A likelihood ratio test indicated that the log-linear model provided a good fit to the presence or absence data for the two pathogens for both 2002 and 2003. There was no significant interaction of the indicator variables for the occurrence of the two pathogen species on the response counts $\left(\chi^{2}\right.$ statistic $=0.03, P=$ 0.854 in 2002; $\chi^{2}$ statistic $=0.72, P=0.38$ in 2003). Thus, the occurrence of one pathogen in sampled diseased leaves in a field was independent of the occurrence of the other.

Occurrence of $\boldsymbol{S}$. nodorum. There was a significant effect of region on the occurrence of $S$. nodorum for both years $\left(\chi^{2}=35.8\right.$, $P<0.001$ for 2002 and $\chi^{2}=31.2, P<0.001$ for 2003) based on the logistic analysis. The regions varied substantially in the estimated probability of occurrence of $S$. nodorum (Table 4). Contrasts for pairs of regions revealed several significant differences (Table 5). In 2002, the estimated probability of occurrence was lowest for regions 1 and $3(\approx 0.23)$, and highest for regions 2,4 , and $5(0.85$ to 0.90$)$. The region 1 estimated probability was less precise than for region 3 (standard error of 0.10 versus 0.05 ) because of the smaller number of fields in region 1 . Thus, there were fewer significant differences in estimated probabilities between region 1 and the rest, compared with region 3 and the rest.

The occurrence of $S$. nodorum was higher in 2003 than in 2002 (Table 2). The lowest probability of $S$. nodorum occurrence was in region 3 (0.58), which was the same region with the lowest probability in 2002. However, region 1 and all the other regions had estimated probabilities of occurrence of at least 0.73 , and there were few significant differences among regions (Table 4).

Occurrence of $\boldsymbol{P}$. tritici-repentis. Region did not have a significant effect on the occurrence of $P$. tritici-repentis in $2002\left(\chi^{2}=\right.$

TABLE 3. Number of fields from which Stagonospora nodorum and Pyrenophora tritici-repentis were obtained ${ }^{\mathrm{a}}$

\begin{tabular}{lccrrr}
\hline & \multicolumn{5}{c}{ P. tritici-repentis } \\
\cline { 2 - 4 } S. nodorum & \multicolumn{3}{c}{2002} & & \multicolumn{2}{c}{2003} \\
\cline { 2 - 5 } \cline { 3 - 5 } & - & + & & - & + \\
\hline- & 125 & 67 & & 50 & 20 \\
+ & 113 & 54 & 248 & 50 \\
\hline
\end{tabular}

a In all, 359 and 368 fields were sampled in Ohio in 2002 and 2003, respectively; - indicates that neither pathogen was isolated and + indicates that the designated pathogen was obtained.

TABLE 2. Distribution of leaf-blotching pathogens collected from seven regions in Ohio in 2002 and 2003

\begin{tabular}{|c|c|c|c|c|c|c|c|c|}
\hline \multirow[b]{2}{*}{ Region $^{\mathrm{a}}$} & \multicolumn{4}{|c|}{2002} & \multicolumn{4}{|c|}{2003} \\
\hline & Counties $^{b}$ & Fields $^{c}$ & Stagonospora $^{\mathrm{d}}$ & Pyrenophora $^{\mathrm{e}}$ & Counties & Fields & Stagonospora & Pyrenophora \\
\hline 1 & 2 & 17 & 4 & 5 & 2 & 9 & 9 & 0 \\
\hline 2 & 4 & 45 & 29 & 12 & 4 & 53 & 46 & 10 \\
\hline 3 & 7 & 78 & 18 & 31 & 7 & 76 & 44 & 29 \\
\hline 4 & 5 & 49 & 33 & 15 & 5 & 48 & 41 & 2 \\
\hline 5 & 7 & 47 & 28 & 18 & 6 & 48 & 43 & 14 \\
\hline 6 & 3 & 20 & 9 & 6 & 2 & 15 & 11 & 4 \\
\hline 7 & 9 & 103 & 46 & 34 & 9 & 119 & 104 & 11 \\
\hline Total & 37 & 359 & 167 & 121 & 35 & 368 & 298 & 70 \\
\hline
\end{tabular}

a Region 1 = northeast, $2=$ north-central, $3=$ northwest, $4=$ southwest, $5=$ south, $6=$ north-central-east, and $7=$ west-central.

b Number of counties in each region.

c Total number of fields sampled in each region. At least one field per county was sampled with a maximum of 15 fields sampled in each county.

d Number of fields where Stagonospora nodorum isolates were obtained from diseased flag leaves.

e Number of fields where Pyrenophora tritici-repentis isolates were obtained from diseased flag leaves. 
3.2, $P=0.78)$, but it did have a significant effect in $2003\left(\chi^{2}=\right.$ $31.0, P<0.001)$. The estimated probability of occurrence of $P$. tritici-repentis varied only between 0.27 and 0.40 in 2002. In 2003, however, there were large differences in occurrence probabilities, which ranged from 0 (region 1) to 0.38 (region 3 ). In general, the prevalence of this pathogen was lower in 2003 than in 2002, which was the opposite trend found for S. nodorum (Table 4). Contrasts for pairs of regions in 2003 revealed several significant differences in the occurrence of P. tritici-repentis (Table 5) in 2003. In general, regions with low probability of occurrence (regions 4 and 7) were significantly different from regions with higher probabilities (regions 3 and 5). Because of the low precision of the estimated probability for region 6 (standard error $=$ 0.11 ), this region generally was not different from the others in terms of pathogen occurrence.

$P$. tritici-repentis race differentiation. The majority of $P$. triticirepentis isolates recovered from leaf samples were races 1 and 2, with rare occasions of race 3 recovery. Race 1 was the predominant race obtained in 2002 (39 isolates, 71\%) and 2003 (32 isolates, 68\%) (Table 6). Regions 2, 4, and 6 had lower occurrence of race 1 than the other regions sampled. Race 2 was obtained from all seven regions, but less frequently than race 1 in
2002 (13 isolates, 24\%) and 2003 (12 isolates, 26\%). Regions 1, 4,5 , and 6 had lower frequency of race 2 isolates than other regions. Race 3 was rarely found in Ohio in 2002 (3 isolates, 5\%) and 2003 (2 isolates, 4\%), occurring in regions 5, 6, and 7.

TABLE 6. Occurrence of Pyrenophora tritici-repentis races in seven regions of Ohio in 2002 and $2003^{\mathrm{a}}$

\begin{tabular}{|c|c|c|c|c|c|c|c|}
\hline \multirow[b]{2}{*}{ Region $^{\mathrm{b}}$} & \multirow[b]{2}{*}{ Total $^{c}$} & \multicolumn{2}{|c|}{ Race 1} & \multicolumn{2}{|c|}{ Race 2} & \multicolumn{2}{|c|}{ Race 3} \\
\hline & & 2002 & 2003 & 2002 & 2003 & 2002 & 2003 \\
\hline 1 & 2 & 2 & 0 & 0 & 0 & 0 & 0 \\
\hline 2 & 7 & 3 & 1 & 1 & 2 & 0 & 0 \\
\hline 3 & 32 & 10 & 13 & 3 & 6 & 0 & 0 \\
\hline 4 & 8 & 4 & 2 & 2 & 0 & 0 & 0 \\
\hline 5 & 18 & 6 & 8 & 0 & 2 & 1 & 1 \\
\hline 6 & 6 & 2 & 1 & 2 & 0 & 1 & 0 \\
\hline 7 & 28 & 12 & 7 & 5 & 2 & 1 & 1 \\
\hline Total & 101 & 39 & 32 & 13 & 12 & 3 & 2 \\
\hline
\end{tabular}

${ }^{a}$ Number of isolates that were identified as each specific race on the set of P. tritici-repentis differential cultivars and lines.

${ }^{\mathrm{b}}$ Region $1=$ northeast, 2 = north-central, $3=$ northwest, 4 = southwest, $5=$ south, $6=$ north-central-east, and $7=$ west-central.

c Total number of isolates recovered in each region in both years.

TABLE 4. Estimated probability of obtaining either Stagonospora nodorum or Pyrenophora tritici-repentis from diseased flag leaves in seven regions of Ohio in 2002 and $2003^{\mathrm{a}}$

\begin{tabular}{|c|c|c|c|c|c|}
\hline \multirow[b]{2}{*}{ Region $^{\mathrm{b}}$} & \multirow[b]{2}{*}{ Total fields sampled } & \multicolumn{2}{|c|}{ S. nodorum } & \multicolumn{2}{|c|}{ P. tritici-repentis } \\
\hline & & 2002 & 2003 & 2002 & 2003 \\
\hline 1 & 26 & $0.24(0.10)$ & $1.00(-)$ & $0.29(0.11)$ & $0.00(-)$ \\
\hline 2 & 98 & $0.64(0.07)$ & $0.87(0.05)$ & $0.27(0.07)$ & $0.19(0.05)$ \\
\hline 4 & 97 & $0.67(0.07)$ & $0.85(0.05)$ & $0.31(0.07)$ & $0.04(0.03)$ \\
\hline 5 & 95 & $0.60(0.09)$ & $0.90(0.04)$ & $0.38(0.07)$ & $0.29(0.07)$ \\
\hline 6 & 35 & $0.45(0.11)$ & $0.73(0.11)$ & $0.30(0.10)$ & $0.27(0.11)$ \\
\hline
\end{tabular}

${ }^{a}$ Species occurrence (i.e., presence or absence) data were analyzed separately using a logistic model in the CATMOD procedure of SAS. Separate analysis was run for each year. Numbers indicate maximum likelihood predicted (i.e. estimated) values for probability of obtaining the species in that region from a diseased flag leaf. Standard error in parenthesis; when probability is 0 or 1 , standard error is undefined (-).

${ }^{\mathrm{b}}$ Region $1=$ northeast, 2 = north-central, 3 = northwest, 4 = southwest, $5=$ south, $6=$ north-central-east, and $7=$ west-central.

TABLE 5. Chi-square values for comparing the probability of Stagonospora nodorum and Pyrenophora tritici-repentis occurrence within fields in seven regions of Ohio during 2002 and $2003^{\mathrm{a}}$

\begin{tabular}{|c|c|c|c|c|c|c|}
\hline \multirow[b]{3}{*}{ Region contrast ${ }^{\mathrm{b}}$} & \multicolumn{4}{|c|}{ S. nodorum } & \multirow{2}{*}{\multicolumn{2}{|c|}{$\begin{array}{c}\text { P. tritici-repentis } \\
2003\end{array}$}} \\
\hline & \multicolumn{2}{|c|}{2002} & \multicolumn{2}{|c|}{2003} & & \\
\hline & $\chi^{2}$ & $P$ value & $\chi^{2}$ & $P$ value & $\chi^{2}$ & $P$ value \\
\hline 1 vs. 3 & 0.00 & 0.9680 & 2.37 & 0.1234 & 2.15 & 0.1421 \\
\hline 1 vs. 4 & 8.62 & 0.0033 & 0.80 & 0.3720 & 0.08 & 0.7737 \\
\hline 1 vs. 5 & 5.91 & 0.0151 & 0.52 & 0.4705 & 1.65 & 0.1991 \\
\hline 1 vs. 6 & 1.81 & 0.1787 & 1.45 & 0.2292 & 1.45 & 0.2292 \\
\hline 2 vs. 4 & 0.09 & 0.7768 & 0.03 & 0.8606 & 4.42 & 0.0356 \\
\hline 2 vs. 5 & 0.23 & 0.6307 & 0.21 & 0.6484 & 1.41 & 0.2346 \\
\hline 2 vs. 6 & 2.12 & 0.1458 & 1.46 & 0.2272 & 0.41 & 0.5207 \\
\hline 2 vs. 7 & 4.80 & 0.0284 & 0.02 & 0.8897 & 3.14 & 0.0764 \\
\hline 3 vs. 4 & 22.52 & $<0.0001$ & 9.49 & 0.0021 & 12.18 & 0.0005 \\
\hline 3 vs. 5 & 15.78 & $<0.0001$ & 12.12 & 0.0005 & 1.04 & 0.3068 \\
\hline 3 vs. 6 & 3.67 & 0.0554 & 1.22 & 0.2700 & 0.70 & 0.4012 \\
\hline 5 vs. 6 & 1.19 & 0.2748 & 2.30 & 0.1290 & 0.03 & 0.8516 \\
\hline 5 vs. 7 & 2.84 & 0.0919 & 0.15 & 0.6939 & 9.71 & 0.0018 \\
\hline 6 vs. 7 & 0.00 & 0.9777 & 2.05 & 0.1522 & 3.67 & 0.0553 \\
\hline
\end{tabular}

${ }^{\text {a }}$ Species were analyzed separately using a logistic model in the CATMOD procedure of SAS. Separate analysis for each year; $\chi^{2}$ and $P$ values were obtained using contrasts of maximum likelihood estimates of logits for pairs of regions.

${ }^{\mathrm{b}}$ Region $1=$ northeast, $2=$ north-central, $3=$ northwest, $4=$ southwest, $5=$ south, $6=$ north-central-east, and $7=$ west-central. 
S. nodorum aggressiveness. The nonparametric analysis (41) of disease ratings indicated that region and cultivar had significant effects $(P<0.02)$ on $S$. nodorum aggressiveness. However, year did not have a significant effect $(P=0.36)$. The interactions were not significant $(P>0.20)$. Isolates recovered from region 1 , representing northeastern Ohio, were lower in aggressiveness (i.e., a lower marginal effect) than isolates from the other six regions (Tables 7 and 8). Median ratings were between 2.3 and 2.8 for region 1 . The relative marginal effect of region 7 , the westcentral area, was significantly greater than for three other regions (Table 8) and had isolates that generally were more aggressive (with a median value of 3 to 4 ). The remaining wheat-growing regions (regions 2 to 6 ) had isolates with similar aggressiveness (similar relative marginal effects).

\section{DISCUSSION}

The distribution of two foliar pathogens of wheat was determined in Ohio in 2002 and 2003. There were significant $(P=$ 0.05 ) differences in the estimated probability of obtaining an isolate of $S$. nodorum from a diseased leaf among different wheatgrowing regions, and the differences varied somewhat between years. $S$. nodorum had a higher probability of being obtained from fields in 2003 than in 2002 regardless of region (Tables 2 and 4). These results indicate that 2003 probably had more favorable environmental conditions for development of this disease, at least relative to other diseases. The large environmental difference between these 2 years occurred from 1 July to 15 July, where there were 7 more days with $>0.28 \mathrm{~cm}$ of precipitation, 13 more days with relative humidity $\geq 75 \%$, and a total of $>12.2 \mathrm{~cm}$ of precipitation in 2003 than in the drier year of 2002. Adequate precipitation early in the season is necessary to favor pycnidium development, pycnidiospore liberation, and dissemination to the seedlings $(3,4)$. Once established in the canopy, pycnidiospores are splash dispersed higher in the canopy $(3,4)$; hence, the additional days in 2003 with precipitation and relative humidity as well as the additional precipitation would encourage more disease.

$P$. tritici-repentis was obtained from the flag leaf samples in both years. There were significant $(P<0.05)$ differences among regions in the probability of obtaining an isolate from diseased leaves only in 2003. Most notably, in the geographically separated northeastern region of Ohio (region 1), no isolates of P. triticirepentis were obtained in 2003 (Table 2). The probability of obtaining a $P$. tritici-repentis isolate was high in both years for region 3, northwest Ohio (Table 4). These results indicate that tan spot has the potential to occur annually, with differences in prevalence among regions most probably due to disease response to environmental conditions. $P$. tritici-repentis has windblown conidia (46) which may be washed out of the air by precipitation events such as occurred in spring 2003 in Ohio. During springs with drier conditions (34), such as 2002 in Ohio, tan spot may be more prevalent relative to Stagonospora leaf blotch, which requires more frequent precipitation events for epidemic development $(3,4)$.

Although there were differences in the occurrence of the two pathogens among regions or years based on the log-linear model analysis, occurrence of one pathogen in sampled diseased leaves in a field was independent of the occurrence of the other pathogen. Thus, any differential effect of environment on occurrence of the pathogens was not large enough to result in a negative association at the field scale. Rather, differential environmental effects likely were manifested at statewide or regional scales. Regardless of variation in the probability of obtaining $S$. nodorum isolates in the seven regions, $S$. nodorum was the predominant leaf-blotching pathogen obtained during both years.

Recovery of $P$. tritici-repentis isolates from flag leaves in 2002 and 2003 indicated that race 1 predominated both years in all regions of Ohio, but race 2 also was collected frequently (Table 6 ). Race 3 was rarer in both years, being recovered from only five fields in three regions (regions 5, 6, and 7). Due to the relatively small sample size and limitations of log-linear or logistic models, statistical analysis could not be conducted on the small number of isolates (a total of 101 isolates from seven regions). Although race 1 was detected in the northeastern Ohio region, only two isolates of $P$. tritici-repentis were obtained from this region in 2002 and no isolates were obtained in 2003. Leaves from fields in region 7 yielded isolates with the most diversity in $P$. tritici-repentis race during both years of sampling. In 2002, region 7 had the most occurrences of race 2; however, in 2003, region 3 had more race 2 isolates identified than the other regions. Races 1 and 2 are well distributed throughout Ohio wheat-growing regions, indicating a need for $P$. tritici-repentis race 1 and 2 resistance in wheat cultivars.

TABLE 8. F values for comparing estimated marginal effects of Stagonospora nodorum aggressiveness for isolates obtained in Ohio in 2002 and 2003

\begin{tabular}{lcc}
\hline Region contrast $^{\mathrm{a}}$ & $F$ value & $P$ value \\
\hline 1 vs. $2-7^{\mathrm{b}}$ & 12.67 & 0.007 \\
2 vs. 3 & 0.54 & 0.51 \\
2 vs. 4 & 1.06 & 0.31 \\
2 vs. 5 & 0.06 & 0.81 \\
2 vs. 6 & 0.12 & 0.73 \\
3 vs. 4 & 0.00 & 0.99 \\
3 vs. 5 & 0.15 & 0.71 \\
3 vs. 6 & 0.06 & 0.81 \\
4 vs. 5 & 0.23 & 0.63 \\
4 vs. 6 & 0.09 & 0.77 \\
5 vs. 6 & 0.01 & 0.91 \\
7 vs. $2-6^{\text {b }}$ & 6.94 & 0.01
\end{tabular}

${ }^{\mathrm{a}}$ Region 1 = northeast, $2=$ north-central, $3=$ northwest, 4 = southwest, $5=$ south, $6=$ north-central-east, and $7=$ west-central.

${ }^{\mathrm{b}}$ Regions 1 and 7 were significantly different from other regions; therefore, a single contrast was used for both regions with the remaining regions of the state.

TABLE 7. Median ratings and estimated relative marginal effects of two susceptible wheat genotypes inoculated with Stagonospora nodorum isolates obtained in Ohio in 2002 and 2003

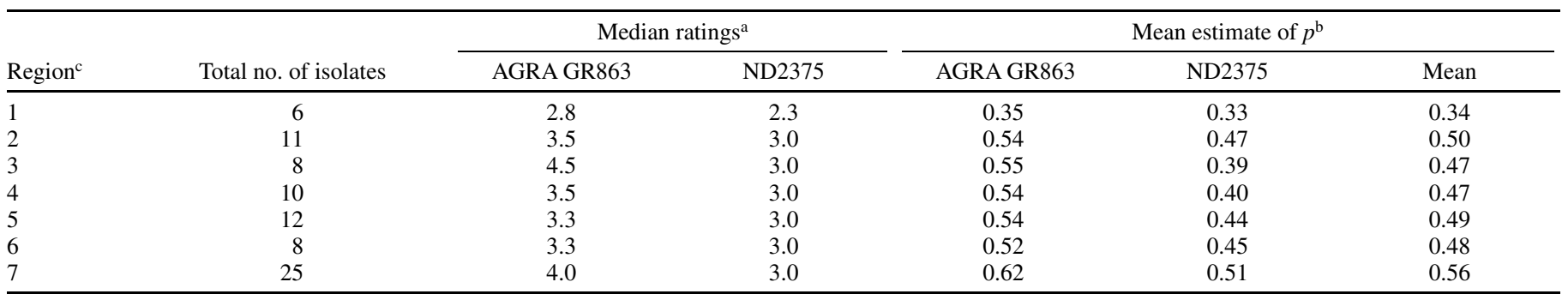

${ }^{a}$ Ratings were obtained 7 days after inoculating each isolate onto 2-week-old seedlings of AGRA GR863 and ND2375. The lesion rating scale was 1 (resistant) to 5 (susceptible) (22). Median ratings were based on 10 seedlings of each cultivar.

${ }^{\mathrm{b}}$ Estimate of marginal region effects was based on mid-ranks of data (41).

${ }^{\mathrm{c}}$ Region 1 = northeast, $2=$ north-central, $3=$ northwest, $4=$ southwest, $5=$ south, $6=$ north-central-east, and $7=$ west-central. 
Aggressiveness differences among $S$. nodorum isolates were evident from region to region but not year to year. The relationship between aggressiveness of isolate and region of Ohio was examined by determining the relative marginal region effects. The geographically separated northeastern region of Ohio was characterized by significantly $(P=0.007)$ less aggressive isolates than other regions (e.g., median lesion rating $=2.75$ on AGRA GR863). Although this region has more snowfall with longer winters and more acid soils than other regions, the impact of these environmental factors on aggressiveness is uncertain. Probably more importantly, northeastern Ohio also is geographically separated from the other wheat-producing areas of the state (Fig. 1) and has fewer fields planted to wheat annually and less than 0.3 million bushels of wheat produced annually per county. The low number of wheat fields planted annually may limit the amount of initial inoculum on a region basis, resulting in limited potential for genetic variability in the geographically isolated population. The direct impact of these factors on aggressiveness is unknown; however, isolates from this region of the state could be used to assess genetic variation in the $S$. nodorum population in Ohio. Interestingly, this region had the highest variability in pathogen occurrence between the 2 years (Table 4 ).

In contrast, isolates from region 7 were statistically $(P=0.01)$ more aggressive than isolates from other regions (e.g., median lesion rating $=4.0$ on AGRA GR863). This region has a high number of fields planted annually to wheat with a high annual production ( 0.6 to 1.3 million bushels wheat produced per county annually) and is surrounded by other regions with similar wheat production per county annually. The producers in region 7 tend to use more reduced tillage, due to their more loamy soils, than other surrounding regions with soils of higher clay contents. Reduced tillage practices have the potential to enhance pathogen survival, sexual reproduction, and production of higher levels of initial inoculum. $S$. nodorum ascospores are windblown in the fall and spring $(3,4)$; hence, crop rotation may not reduce infection events when neighboring fields with wheat residue are managed using reduced tillage. Therefore, region 7 has conditions that may increase the likelihood of genetic recombination possibly, leading to more aggressive isolates than some other regions sampled. The aggressiveness studies indicate that the majority of Ohio wheat growing regions (regions 2 to 6 ) have isolates of $S$. nodorum with similar aggressiveness levels, and differences in cultivar reactions from one location to another in these regions probably are not due to difference in aggressiveness.

In conclusion, the results of this study indicate that $S$. nodorum is the most prevalent leaf-blotching pathogen in Ohio. Studies to determine differences in aggressiveness of $S$. nodorum isolates obtained in the seven wheat-growing regions indicated that, across the majority of these regions, there were no major differences in aggressiveness. $P$. tritici-repentis also was present in all seven regions in at least 1 year, indicating that this pathogen also is widespread in Ohio. There was no positive or negative association between $S$. nodorum and $P$. tritici-repentis occurrence on flag leaves during the 2 years of this study because, at the field scale, both pathogens sometimes occurred on the same leaf $\approx 15 \%$ of the time. Positive identification of leaf-blotching pathogen was not possible in the field due to the similarity of lesion types caused by $S$. nodorum and $P$. tritici-repentis $(5,11)$. Wheat researchers need to recognize the confounding effect caused by the possible presence of these two pathogens on cultivar resistance scoring when evaluating cultivar reactions to foliar pathogens in field nurseries in Ohio.

\section{ACKNOWLEDGMENTS}

Salaries and research support were provided by State and Federal Funds appropriated to the Ohio Agricultural Research and Development Center, The Ohio State University. We thank A. L. Johnston for technical assistance and T. Friesen and his staff for assistance and instruction on $P$. tritici-repentis race determination.

\section{LITERATURE CITED}

1. Ali, S., and Francl, L. J. 2003. Population race structure of Pyrenophora tritici-repentis prevalent on wheat and noncereal grasses in the Great Plains. Plant Dis. 87:418-422.

2. Arseniuk, E. Gòral, T., Sava, W., Czembor, H. J., Krysiak, H., and Scharen, A. L. 1998. Transmission of Stagonospora nodorum and $\mathrm{Fu}$ sarium spp. on triticale and wheat seed and the effect of seedborne Stagonospora nodorum on disease severity under field conditions. J. Phytopathol. 146:339-345.

3. Arseniuk, E. Gòral, T., and Scharen, A. L. 1998. Seasonal patterns of spore dispersal of Phaeosphaeria spp. and Stagonospora spp. Plant Dis. 82:187-194.

4. Bathgate, J. A., and Loughman, R. 2001. Ascospores are a source of inoculum of Phaeosphaeria nodorum, $P$. avenaria $\mathrm{f}$. sp. avenaria, and Mycosphaerella graminicola in Western Australia. Aust. Plant Pathol. 30:317-322.

5. Bhathal, J. S., Loughman, R., and Speijers, J. 2003. Yield reduction in wheat in relation to leaf disease from yellow (tan) spot and Septoria nodorum blotch. Eur. J. Plant Pathol. 109:435-443.

6. Bockus, W. W., and Claassen, M. M. 1992. Effects of crop rotation and residue management practices on severity of tan spot winter wheat. Plant Dis. 76:633-636.

7. Brunner, E., and Puri, M. L. 2001. Nonparametric methods in factorial designs. Stat. Pap. 42:1-52.

8. Ciuffetti, L. M., Francl, L. J., Ballance, G. M., Bockus, W. W., Lamari, L., Meinhardt, S. W., and Rasmussen, J. B. 1998. Standardization of toxin nomenclature in the Pyrenophora tritici-repentis/wheat interaction. Can. J. Plant Pathol. 20:421-424.

9. Collett, D. 2003. Modeling Binary Data. Chapman and Hall, Boca Raton, FL

10. Du, C. G., Nelson, L. R., and McDaniel, M. E. 1999. Partial resistance to Stagonospora nodorum in wheat. Pages 160-162 in: Septoria and Stagonospora Diseases of Cereals: A Compilation of Global Research. Published online. International Maize and Wheat Improvement Center (CIMMYT), Mexico, D.F

11. Engle, J. S. 2005. Pathogenic characterization, distribution in Ohio and genotype reaction to Stagonospora nodorum and Pyrenophora triticirepentis. $\mathrm{Ph}$.D. dissertation, The Ohio State University, Wooster.

12. Eyal, Z., Scharen, A. L., Prescott, J. M., and van Ginkel, M. 1987. The Septoria Diseases of Wheat: Concepts and Methods of Disease Management. International Maize and Wheat Improvement Center (CIMMYT), Mexico, D.F.

13. Fernandez, M. R., DePauw, R. M., Clarke, J. M., and Fox, S. L. 1998. Discoloration of wheat kernels by Pyrenophora tritici-repentis. Can. J. Plant Pathol. 20:380-383.

14. Fried, P. M., and Meister, E. 1987. Inheritance of leaf and head resistance of winter wheat to Septoria nodorum in a diallel cross. Phytopathology 77:1371-1375

15. Friesen, T. L., Ali, S., Kianian, S. Francl, L. J., and Rasmussen, J. B. 2003. Role of host sensitivity to Ptr Tox A in development of tan spot of wheat. Phytopathology 93:397-401.

16. Friesen, T. L., and Faris, J. M. 2004. Molecular mapping of resistance to Pyrenophora tritici-repentis race 5 and sensitivity to Ptr ToxB in wheat. Theor. Appl. Genet. 109:464-471.

17. Gamba, F. M., Laman, L., and Brûlé-Babel, A. L. 1998. Inheritance of race-specific necrotic and chlorotic reactions induced by Pyrenophora tritici-repentis in hexaploid wheats. Can. J. Plant Pathol. 20:401-407.

18. Garrett, K. A., Madden, L. V., Hughes, G., and Pfender, W. F. 2004. New applications of statistical tools in plant pathology. Phytopathology 94:999-1003.

19. Gilbert, J., and Tekauz, A. 1993. Reaction of Canadian spring wheats to Septoria nodorum and the relationship between disease severity and yield components. Plant Dis. 77:398-402.

20. Keller, S. M., Wolfe, M. S., McDermott, J. M., and McDonald, B. A. 1997. High genetic similarity among populations of Phaeosphaeria nodorum across wheat cultivars and regions in Switzerland. Phytopathology 87:1134-1139.

21. Krupinsky, J. M. 1999. Influence of cultural practices on Septoria/ Stagonospora diseases. Pages 105-110 in: Septoria and Stagonospora Diseases of Cereals: A Compilation of Global Research. Published online. International Maize and Wheat Improvement Center (CIMMYT), Mexico, D.F.

22. Lamari, L., and Bernier, C. C. 1989. Evaluation of wheat lines and cultivars to tan spot (Pyrenophora tritici-repentis) based on lesion type. Can. J. Plant Pathol. 11:49-56. 
23. Lamari, L., Strelkov, S. E., Yahyaoui, A., Orabi, J., and Smith, R. B. 2003. The identification of two new races of Pyrenophora tritici-repentis from the host center of diversity confirms a one-to-one relationship in tan spot of wheat. Phytopathology 93:391-396.

24. Large, E. C. 1954. Growth stages in cereals. Illustration of the Feekes scale. Plant Pathol. 3:128-129.

25. Liu, Z. H., Friesen, T. L., Rasmussen, J. B., Ali, S., Meinhardt, S. W., and Faris, J. D. 2004. Quantitative trait loci analysis and mapping of seedling resistance to Stagonospora nodorum leaf blotch in wheat. Phytopathology 94:1061-1067.

26. Loughman, R., and Thomas, G. J. 1992. Fungicide and cultivar control of Septoria diseases of wheat. Crop Prod. 11:349-354.

27. Manandahar, J. B., and Cunfer, B. M. 1991. An improved selective medium for the assay of Septoria nodorum from wheat seed. Phytopathology 81:771-773.

28. Manning, V. A., Andrie, R. M., Trippe, A. F., and Ciuffetti, L. M. 2004. Ptr ToxA requires multiple motifs for complete activity. Mol. PlantMicrobe Interact. 17:491-501.

29. Martinez, J. P., Oesch, N. W., and Ciuffetti, L. M. 2004. Characterization of the multiple-copy host-selective toxin gene, ToxB, in pathogenic and nonpathogenic isolates of Pyrenophora tritici-repentis. Mol. PlantMicrobe Interact. 17:467-474.

30. Mead, R., Curnow, R. N., and Hasted, A. M. 1993. Statistical Methods in Agriculture and Experimental Biology. 2nd ed. Chapman and Hall, Boca Raton, FL.

31. Milus, E. A., and Chalkley, D. B. 1997. Effect of previous crop, seedborne inoculum, and fungicides on development of Stagonospora blotch. Plant Dis. 81:1279-1283.

32. Nelson, L. R., Morey, D. D., and Brown, A. R. 1974. Wheat cultivar responses to severe glume blotch in Georgia. Plant Dis. Rep. 58:21-23.

33. Nutter, F. W., Jr. 2002. Disease assessment. Pages 312-323 in: Encyclopedia of Plant Pathology. O. C. Maloy and T. D. Murrary, eds. John Wiley and Sons, New York.

34. Perello, A., Moreno, V., Simón, M. R., and Sisterna, M. 2003. Tan spot of wheat (Triticum aestivum L.) infection at different stages of crop development and inoculum type. Crop Prot. 22:157-169.

35. Rees, R. G., and Platz, G. J. 1990. Sources of resistance to Pyrenophora tritici-repentis in bread wheats. Euphytica 45:59-69.
36. Riede, C. R., Frand, L. J., Anderson, J. A., Jordahl, J. G., and Meinhardt, S. W. 1996. Additional sources of resistance to tan spot of wheat. Crop Sci. 36:771-777.

37. Scharen, A. L. 1999. Biology of the Septoria/Stagonospora pathogens: An overview. Pages 19-22 in: Septoria and Stagonospora Diseases of Cereals: A Compilation of Global Research. Published online. International Maize and Wheat Improvement Center (CIMMYT), Mexico, D.F.

38. Scharen, A. L., Eyal, Z., Huffman, M. D., and Prescott, J. M. 1985. The distribution and frequency of virulence genes in geographically separated populations of Leptosphaeria nodorum. Phytopathology 75:1463-1468.

39. Shah, D. A., and Bergstrom, G. C. 1993. Assessment of seedborne Stagonospora nodorum in New York soft white winter wheat. Plant Dis. 77:468-471.

40. Shah, D. A., and Bergstrom, G. C. 1999. Epidemiology of seedborne Stagonospora nodorum: A case study on New York winter wheat. Pages 102-104 in: Septoria and Stagonospora Diseases of Cereals: A Compilation of Global Research. Published online. International Maize and Wheat Improvement Center (CIMMYT), Mexico, D.F.

41. Shah, D. A., and Madden, L.V. 2004. Nonparametric analysis of ordinal data in designed factorial experiments. Phytopathology 94:33-43.

42. Shaner, G., and Buechley, G. 1995. Epidemiology of leaf blotch of soft red winter wheat caused by Septoria tritici and Stagonospora nodorum. Plant Dis. 79:928-938.

43. Thomson, S. K. 1992. Sampling. John Wiley and Sons, New York.

44. van Ginkel, M., and Rajaram, S. 1999. Breeding for resistance to the Septoria/Stagonospora blights of wheat. Pages 117-126 in: Septoria and Stagonospora Diseases of Cereals: A Compilation of Global Research. Published online. International Maize and Wheat Improvement Center (CIMMYT), Mexico, D.F.

45. Verreet, J. A., and Hoffmann, G. M. 1990. A biologically oriented threshold decision model for control of epidemics of Septoria nodorum in wheat. Plant Dis. 74:731-738.

46. Wiese, M. V. (ed.) 1987. Compendium of Wheat Diseases, 2nd ed. The American Phytopathological Society, St. Paul, MN.

47. Zhang, W., and Jin, Y. 1998. Sensitivity to Ptr ToxA and tan spot infection responses in Aegilops/Triticum complex. Can. J. Plant Pathol. 20:415-418.

48. Zillinsky, F. J. 1983. Common diseases of small grain cereals: A guide to identification. International Maize and Wheat Improvement Center (CIMMYT), Mexico, D.F 